\title{
DETECCIÓN Y RESISTENCIA A ANTIBIÓTICOS DE Escherichia coli Y Salmonella EN AGUA Y SUELO AGRÍCOLA
}

\author{
DETECTION AND ANTIBIOTIC RESISTANCE OF Escherichia coli AND Salmonella IN WATER AND \\ AGRICULTURAL SOIL
}

\author{
Osvaldo López Cuevas, Josefina León Félix, Maribel Jiménez Edeza y Cristóbal Chaidez Quiroz*
}

\author{
Centro de Investigación en Alimentación y Desarrollo, Coordinación Culiacán. Carretera a Eldorado Km. 5.5, Apartado Postal 32-A. C.P. 80210, \\ Culiacán, Sin. México. Tel. (667) 76055 36. Fax (667) 7605537.

\section{RESUMEN}

Con el fin de cuantificar a Escherichia coli y determinar la presencia de Salmonella, se tomaron y analizaron 51 muestras de agua y 23 muestras de suelo en cuatro regiones del Valle de Culiacán, Sinaloa, México. Además, se determinó el perfil de resistencia de Salmonella a ampicilina, ciprofloxacino, trimetoprim-sulfametoxazol, tetraciclina, estreptomicina y gentamicina, y de los últimos tres antimicrobianos en $E$. coli. En las muestras de suelo analizadas hubo ausencia de $\boldsymbol{E}$. coli y Salmonella, mientras que en las de agua se logró aislar 20 cepas de Salmonella. La serotipificación mostró que 13 cepas de Salmonella fueron Typhimurium, 2 de Infantis, 1 de Anatum, 1 de Agona, 1 de Oranienburg, 1 de Minnesota y 1 de Give. De las muestras de agua analizadas $98 \%$ estaban contaminadas con $E$. coli, con mínimos de 4 UFC/100 mL, máximos de $4.5 \times 10^{5} \mathrm{UFC} / 100 \mathrm{~mL}$ y un promedio de $1.6 \times 10^{4} \mathrm{UFC} / 100 \mathrm{~mL}$, de las cuales se seleccionaron cepas para evaluar el perfil de resistencia a antimicrobianos. Todas las cepas de Salmonella fueron susceptibles a ampicilina, ciprofloxacino y trimetoprim-sulfametoxazol y 12 presentaron resistencia a tetraciclina. De las 46 cepas de $E$. coli analizadas, 9 fueron resistentes a tetraciclina, 38 fueron resistentes a estreptomicina y sólo una cepa fue resistente a gentamicina; mientras que 23 cepas presentaron resistencia intermedia. Todas las cepas de Salmonella tuvieron altos niveles de resistencia a $\mathrm{CuSO}_{4} \cdot 5 \mathrm{H}_{2} \mathrm{O}$ en dosis entre 1200 y $1600 \mu \mathrm{g} \mathrm{mL}^{-1}$ del antimicrobiano. El presente estudio demostró la existencia de diversos serotipos de Salmonella y altos niveles de $E$. coli en agua del Valle de Culiacán.

Palabras clave: Salmonella, Escherichia coli, resistencia antimicrobiana, serotipificación.

\section{SUMMARY}

In order to quantify Escherichia coli and to identify presence of Salmonella, 51 water and 23 soil samples in four regions of the Culiacán Valley at Sinaloa, México, were taken and analyzed. In addition, resistance profile of Salmonella to ampicilline, ciprofloxacin, trimethoprim-sulfamethoxazole, tetracycline, streptomycine and gentamicin were determined, and the last three antimicrobials in $E$. coli. Soil samples analyzed had absence of both $E$. coli and Salmonella, whereas water contained 20 strains of Salmonella. Serotyping showed that 13 Salmonella strains were Typhimurium, 2 were Infantis, 1 Anatum, 1 Agona, 1 Oranienburg,
1 Minnesota and 1 Give. Analyzed water samples were $98 \%$ contaminated with $E$. coli, with minimums of $4 \mathrm{CFU} / 100 \mathrm{~mL}$, maximums of $4.5 \times 10^{5} \mathrm{CFU} / 100 \mathrm{~mL}$ and an average of $1.6 \times 10^{4}$ CFU/100 mL; some strains were isolated to evaluate the antimicrobials resistance profile. All isolated strains of Salmonella were susceptible to ampicilline, ciprofloxacin and trimethoprimsulfamethoxazole and 12 were resistance to tetracycline. Of the 46 strains of $E$. coli analyzed, 9 were resistant to tetracycline, 38 were resistant to streptomycine and one strain was resistant to gentamicina; 23 strains were of intermediate resistance. All Salmonella strains had high levels of resistance to $\mathrm{CuSO}_{4} \cdot 5 \mathrm{H}_{2} \mathrm{O}$ in dosages between 1200 and $1600 \mu \mathrm{g} \mathrm{mL}^{-1}$ of the copper concentration. The present study demonstrated the existence of numerous Salmonella serotypes and high levels of $E$. coli in water from the Culiacán Valley.

Index words: Salmonella, Escherichia coli, antimicrobial resistance, serotyping.

\section{INTRODUCCIÓN}

Las frutas y hortalizas de consumo en fresco pueden servir como vehículos de una amplia diversidad de bacterias, parásitos y virus patógenos al hombre (Beuchat, 1996). La contaminación microbiana de frutas y hortalizas frescas, agua de riego y suelo de cultivo, son consideradas las principales fuentes que ocasionan la pérdida de la inocuidad de alimentos (Gill et al., 2003). La forma común y además autorizada para verificar la ausencia de contaminación de origen fecal es la detección de coliformes fecales y Escherichia coli (NOM-001-ECOL1996; UM-FDA, 2002), ya que un número elevado de estas bacterias indicadoras sugiere la presencia de patógenos específicos, como Salmonella o patotipos de Escherichia coli.

Durante el periodo de 2000-2002 se reportaron tres brotes diarreicos por el consumo de melón "Cantaloupe" en Estados Unidos y Canadá, en los que se identificó a 
Salmonella ser. Poona como el agente causal; el agua de riego y el agua de uso en empacadoras fueron señalados como posibles vehículos de la bacteria (CDC, 2002). También se confirmó que E. coli $\mathrm{O} 157: \mathrm{H} 7$ ha provocado casos de gastroenteritis por el consumo de lechugas, germinados de alfalfa, jugo de naranja, zanahorias y espinacas (Buck et al., 2003).

En México, cada año se reportan alrededor de 110000 casos de salmonelosis asociados al consumo de agua y alimentos contaminados (DGE, 2006), y pocas veces se identifica el origen de las bacterias. Aunque la mayoría de infecciones por Salmonella son autolimitantes ( 3 a 5 d) y no requieren tratamiento antimicrobiano, los niños, adultos mayores y pacientes con enfermedad severa o inmunocomprometidos pueden experimentar episodios diarreicos y requerir la prescripción de antibióticos como ampicilina, cloramfenicol y trimetoprim-sulfametoxazol (Miko et al., 2005). Además, la automedicación es una práctica común, la cual no establece un buen tratamiento ni en dosis ni en tiempo. Los medicamentos más autorrecetados son ciprofloxacino, aminoglucósidos y tetraciclinas (Bada-Alambedji et al., 2006).

Diversos reportes han mostrado un incremento en la emergencia de Salmonella y $E$. coli con niveles significativos de resistencia a los antimicrobianos (Duffy et al., 2005; Musgrove et al., 2006). En adición a la automedicación terapéutica, en veterinaria y en agricultura se aplican antimicrobianos de manera indiscriminada (Miko et al., 2005). En los últimos 50 años, el valle agrícola de Culiacán, Sinaloa, ha sido considerado como la principal zona productora y exportadora de hortalizas en México; no obstante, en esta zona los agricultores con frecuencia sufren pérdidas económicas por efecto de bacterias fitopatógenas (Erwinia, Xanthomonas, Clavibacter, Pseudomonas) en los cultivos, por lo que constantemente aplican grandes volúmenes de antimicrobianos para su control. Los bactericidas agrícolas comúnmente utilizados son mezclas de antimicrobianos, como tetraciclina, estreptomicina y gentamicina, con sulfato de cobre $\left(\mathrm{CuSO}_{4}\right)$ (SAGARPA, 2007). El cobre se utiliza como ingrediente activo en preparaciones bactericidas y fungicidas agrícolas desde hace más de 100 años; sin embargo, en la década de los 80's se reportó tolerancia al cobre en bacterias fitopatógenas, como Xanthomonas campestris pv. vesicatoria (Martin et al., 2004).

Las bacterias también adquieren resistencia a los antimicrobianos a través de transferencia vertical $u$ horizontal de información genética. Chatterjee y Starr (1972) observaron que cepas de E. coli fueron capaces de transferir factores de resistencia a tetraciclina (Factor tet $\mathrm{R}$ ) a nueve especies de Erwinia; en este mismo estudio se demostró que Shigella flexneri pudo transferir un factor de múltiple resistencia a cloramfenicol, estreptomicina y tetraciclina, a cuatro cepas de Erwinia. Actualmente se sabe que los elementos genéticos conocidos como integrones tienen la habilidad de capturar grupos de genes del ambiente (agua, suelo), e incorporarlos mediante recombinación en sitios específicos (Miko et al., 2005).

Cepas en el ambiente de Salmonella y E. coli pueden estar en contacto con altas concentraciones de antimicrobianos o con especies resistentes a éstos, por lo que es factible la selección en campo de cepas resistentes.

Este estudio se llevó a cabo debido a la escasa información acerca de la presencia de microorganismos indicadores y patógenos en agua y suelo de uso agrícola en el Valle de Culiacán; también se desconoce la diversidad de serotipos de Salmonella que pueden estar presente en esta región. Además, el uso permanente de antimicrobianos en el sector agrícola hace suponer que pueden tener efectos sobre la resistencia de los microorganismos. Por ello, los objetivos de este trabajo fueron: (i) Cuantificar la presencia de E. coli y determinar los serotipos de Salmonella en agua y suelo de uso agrícola del Valle de Culiacán, Sinaloa; (ii) Evaluar la resistencia de Salmonella a los antimicrobianos ampicilina, ciprofloxacino, trimetoprim-sulfametoxazol, tetraciclina, estreptomicina y gentamicina, y el de E. coli a tetraciclina, estreptomicina y gentamicina; y, (iii) Determinar la concentración mínima inhibitoria (CMI) de sulfato de cobre $\left(\mathrm{CuSO}_{4} \cdot 5 \mathrm{H}_{2} \mathrm{O}\right)$ en Salmonella.

\section{MATERIALES Y MÉTODOS}

\section{Recolección de muestras}

Se colectaron 51 muestras de agua y 23 de suelo agrícola durante el periodo del 2 de enero al 15 de mayo de 2005, porque hay una alta actividad agrícola durante este periodo, para identificar la presencia de Salmonella y cuantificar E. coli. Las muestras de agua y suelo se tomaron de canales de riego y campos de cultivo, respectivamente, del valle agrícola de Culiacán, Sinaloa. Para facilitar el estudio, el Valle se dividió en cuatro regiones (Figura 1). Los lugares de muestreo se eligieron con base en el tipo de cultivos (tomates, pepinos, pimientos y berenjenas); y en la aplicación de productos agrícolas formulados con tetraciclina, estreptomicina, gentamicina o sulfato de cobre, que se utilizan comúnmente para el control de bacterias fitopatógenas. 


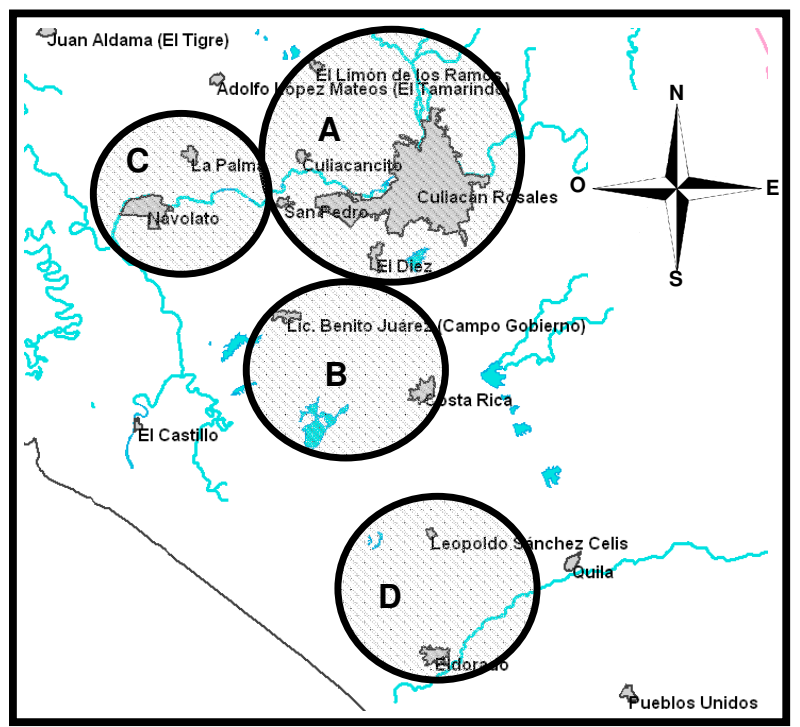

Figura 1. Valle de Culiacán dividido en las regiones de: A) Culiacán; B) Villa Juárez; C) Navolato y D) Eldorado.

Las muestras de agua se colectaron en frascos de polipropileno estériles de $1 \mathrm{~L}$ de capacidad, debidamente etiquetados y cerrados. A cada litro de muestra se le agregó $0.2 \mathrm{~mL}$ de tiosulfato de sodio $\left(\mathrm{Na}_{2} \mathrm{~S}_{2} \mathrm{O}_{3}\right)$ a $10 \%$ (Faga Lab, México) para inactivar el cloro residual que pudiera estar presente. Las muestras de suelo se extrajeron con cucharas metálicas estériles, de cinco puntos seleccionados aleatoriamente en cada parcela. Se tomaron aproximadamente $50 \mathrm{~g}$ de suelo por punto a una profundidad no mayor de $5 \mathrm{~cm}$, y se colocaron en bolsas estériles (Ziploc $\circledast$ ). Las muestras se trasladaron en frío al Laboratorio de Microbiología Ambiental y de Alimentos en Culiacán, para ser procesadas en las primeras $6 \mathrm{~h}$ después de la toma de muestra.

\section{Análisis microbiológico del agua de uso agrícola}

Con el objetivo de analizar una mayor cantidad de muestra para el aislamiento de Salmonella del agua de uso agrícola, se modificó la metodología descrita en el Compendio de Métodos Estándar para el Análisis de Agua y Agua Residual (APHA, 1999), y obtener un concentrado de la muestra. Se tomaron $300 \mathrm{~mL}$ de agua de uso agrícola $\mathrm{y}$ se repartieron uniformemente en seis tubos para centrífuga de $50 \mathrm{~mL}$ (Nalgene $\left.{ }^{\circledR}\right)$, se centrifugaron a 13 $750 \times g$ por $10 \mathrm{~min}$ a $4{ }^{\circ} \mathrm{C}$ (IEC MultiRF®). El sobrenadante se eliminó por succión con pipeta automática de $10 \mathrm{~mL}$ (Thermo®) y se dejó aproximadamente $2 \mathrm{~mL}$ de agua; el remanente se resuspendió por agitación en vórtex por $20 \mathrm{~s}$.

El contenido de cada tubo se colocó en un matraz estéril de $50 \mathrm{~mL}$ y se agitó manualmente. Muestras de 0.1
$\mathrm{mL}$ se adicionaron a tubos con $9.9 \mathrm{~mL}$ de caldo de enriquecimiento Rappaport Vassiliadis (BD Difco®, Maryland, EE. UU.) y se incubó por $20 \pm 2 \mathrm{~h}$ a $37^{\circ} \mathrm{C}$. Transcurrido el tiempo de incubación, las muestras se sembraron por estriado con un asa de platino estéril en agar entérico Hektoen (BD Bioxón®, México) y agar XLD (BD Bioxón®, México) y se incubaron por $20+2 \mathrm{~h}$ a 37 ${ }^{\circ} \mathrm{C}$. Se seleccionaron colonias típicas de Salmonella de los medios selectivos (colonias pequeñas con el centro negro y un halo transparente, como describe el fabricante), se aislaron en agar de soya y tripticaseína (TSA, siglas en inglés) (BD Bioxón ${ }^{\circledR}$, México) y se almacenaron a $4{ }^{\circ} \mathrm{C}$ para su posterior confirmación por la técnica de reacción en cadena de la polimerasa (PCR, siglas en inglés).

Para el aislamiento de Escherichia coli se utilizó la técnica de filtración por membrana, descrita en el Compendio de Métodos Estándar para el Análisis de Agua y Agua Residual (APHA, 1999), mediante tren de filtración, embudos de $150 \mathrm{~mL}$, membranas de nitrocelulosa con poros de $0.45 \mu \mathrm{m}$ de diámetro, matraz Kitasato de 2 L de capacidad para recolección del filtrado y bomba de vacío (E-1500 Felisa ${ }^{\circledR}$, México) a una presión de $1 \mathrm{~kg} \mathrm{~cm}^{-2}$. Se filtraron volúmenes de $0.1,1$ y $10 \mathrm{~mL}$ de cada muestra, y la membrana fue colocada sobre la superficie del agar ECC (CHROMagar ${ }^{\circledR}$, Paris, Francia), lo que permite la diferenciación de $E$. coli del resto de los coliformes fecales. Las placas se incubaron por $24 \mathrm{~h}$ a 45 ${ }^{\circ} \mathrm{C}$; transcurrido el tiempo de incubación, se cuantificó la presencia de E. coli con base en las características de la colonia presentada en agar ECC, como son colonias medianas de color azul debido a la fermentación del ácido glucorónico del medio.

Los aislados de Salmonella que resultaron positivos por PCR y una o dos colonias de E. coli de cada muestra se cultivaron en caldo de soya y tripticaseína (TSB, siglas en inglés) y se almacenaron en glicerol a $40 \%$, a $-20{ }^{\circ} \mathrm{C}$ para su preservación y análisis posteriores.

\section{Confirmación de Salmonella por PCR}

Se utilizó la metodología descrita por Chiu y Ou (1996) para la confirmación de Salmonella por PCR. Se lisó 1.5 $\mathrm{mL}$ del cultivo bacteriano $\left(2.5 \times 10^{8}\right.$ células $\left./ 1.5 \mathrm{~mL}\right)$ en agua hirviendo por $10 \mathrm{~min}$. La reacción para PCR consistió en buffer de amplificación para PCR 1X libre de $\mathrm{MgCl}_{2}$ (Promega ${ }^{\circledR}$, EE. UU.), $1.5 \mathrm{mM}$ de $\mathrm{MgCl}_{2}, 200$ $\mu \mathrm{M}$ de cada deoxinucleótido trifosfato (dATP, dGTP, dTTP y dCTP), $1 \mu \mathrm{M}$ de cada iniciador, invA-1 (Sentido): 5'-ACA GTG CTC GTT TAC GAC CTG AAT-3' e invA2 (Antisentido): 5'-AGA CGA CTG GTA CTG ATC GAT AAT-3' (Sigma ${ }^{\circledR}, \quad$ USA), 0.625 U de Taq DNA polimerasa (Promega ${ }^{\circledR}$, USA), $1 \mu \mathrm{L}$ del lisado bacteriano 
y agua nanopura estéril, para un volumen final de $25 \mu \mathrm{L}$. La amplificación se llevó a cabo en un termociclador de gradiente (Mastercyclerß; Eppendorf) mediante un ciclo a $94{ }^{\circ} \mathrm{C}$ por $1 \mathrm{~min}$ y 30 ciclos de $30 \mathrm{~s}$ a $94{ }^{\circ} \mathrm{C}, 30 \mathrm{~s}$ a 56 ${ }^{\circ} \mathrm{C}, 2$ min a $72{ }^{\circ} \mathrm{C}$; y, un ciclo de extensión final a $72{ }^{\circ} \mathrm{C}$ por $10 \mathrm{~min}$; por último, la reacción de amplificación se estabilizó a $4{ }^{\circ} \mathrm{C}$. Los productos de PCR se separaron en geles de agarosa a $1 \%(\mathrm{p} / \mathrm{v})$ con amortiguador TAE $1 \mathrm{X}$ (Eppendorf®; EE. UU.) por $45 \mathrm{~min}$ a $70 \mathrm{~V}$, se tiñieron con bromuro de etidio $\left(0.33 \mathrm{mg} \mathrm{mL}^{-1}\right)$, y se identificaron como positivas las muestras que amplificaron un fragmento de tamaño molecular de $244 \mathrm{pb}$. Los fragmentos obtenidos se visualizaron en un transiluminador de luz ultravioleta (Chiu y Ou, 1996).

\section{Análisis microbiológico del suelo de uso agrícola}

Se empleó la metodología para el análisis de alimentos sólidos descrita en APHA (2001); para esto, se pesaron 25 $\mathrm{g}$ de muestra y se agregaron a $225 \mathrm{~mL}$ de agua peptonada amortiguada a $1 \%$ (BD Difcoß; Maryland, EE. UU.) y se incubó por $20-24 \mathrm{~h}$ a $37^{\circ} \mathrm{C}$. Para el aislamiento de Salmonella se tomó $0.1 \mathrm{~mL}$ del cultivo en agua de peptona y se agregó a $9.9 \mathrm{~mL}$ de caldo de enriquecimiento Rappaport Vassiliadis (BD Difcoß; Maryland, EE. UU.). El procedimiento de aislamiento y confirmación de Salmonella en muestras de suelo, se hizo con el protocolo descrito en la sección de análisis microbiológico de agua de uso agrícola. Para el aislamiento y cuantificación de $E$. coli y coliformes fecales, se tomaron alícuotas del cultivo en agua peptonada, para hacer diluciones de 1:10, 1:100 y $1: 1000$, las cuales se procesaron por el método de filtración por membrana, como se describió anteriormente.

\section{Identificación de serotipos de Salmonella y pruebas de resistencia a los antimicrobianos}

Las cepas de Salmonella aisladas y confirmadas por PCR, se sembraron en TSA en tubos inclinados, se incubaron por $18-24 \mathrm{~h}$ a $37{ }^{\circ} \mathrm{C}$ y se enviaron al Instituto de Diagnóstico y Referencia Epidemiológicos (InDRE) en la ciudad de México, para su completa serotipificación.

Las pruebas de resistencia a los antimicrobianos se hicieron por triplicado con el método de difusión en disco, descrito en el National Commitee for Clinical Laboratory Standard (NCCLS, 2003). Se utilizó una cepa de E. coli ATCC25922 como control de calidad interno. Los antimicrobianos utilizados y sus correspondientes concentraciones fueron: ampicilina $(10 \mu \mathrm{g})$, ciprofloxacino (5 $\mu \mathrm{g})$, trimetoprim-sulfametoxazol $(1.25 / 23.75 \mu \mathrm{g})$, tetraciclina $(30 \mu \mathrm{g})$, estreptomicina $(10 \mu \mathrm{g})$ y gentamicina $(10 \mu \mathrm{g})$ (BBL Sensi-Disc®; Becton Dickinson, EE. UU.) para Salmonella, y los últimos tres antimicrobianos se utilizaron en las pruebas de resistencia para E. coli.

Para la determinación de la concentración mínima inhibitoria $(\mathrm{CMI})$ de sulfato de cobre $\left(\mathrm{CuSO}_{4} \cdot 5 \mathrm{H}_{2} \mathrm{O}\right)$ contra Salmonella se determinó la concentración de sulfato de cobre en un producto comercial, con el método oficial para determinación de cobre por absorción atómica (AOAC 995.06, 1998). La CMI se desarrolló con el método de dilución en agar, descrito en el National Commitee for Clinical Laboratory Standard (NCCLS, 1997), y se consideró como CMI a la mínima concentración de sulfato de cobre capaz de inhibir por completo el crecimiento de Salmonella.

\section{RESULTADOS Y DISCUSIÓN}

\section{Aislamiento y serotipificación de Salmonella}

De las 51 muestras de agua de riego colectadas, 20 resultaron positivas a Salmonella. De las muestras positivas se aislaron 20 cepas de Salmonella, las cuales se confirmaron por PCR (Cuadro 1). Las muestras de agua se colectaron en las orillas de canales de riego, entre la interfase agua-suelo o agua-concreto. Duffy et al. (2005) analizaron muestras de frutos, superficies, agua de riego y suelo, y encontraron la mayor contaminación por Salmonella en agua de irrigación; estos autores propusieron que la interfase que se forma entre el agua y el suelo en los canales, puede servir de reservorio de microorganismos indicadores de contaminación fecal.

Cuadro 1. Presencia de Salmonella y cuantificación de $\boldsymbol{E}$. coli en agua del Valle de Culiacán, Sinaloa, México.

\begin{tabular}{cccrrr}
\hline \multirow{2}{*}{ Región } & Salmonella $^{\dagger}$ & \multicolumn{4}{c}{ E. coli } \\
& & MP $^{\dagger \dagger}$ & Mín & \multicolumn{1}{c}{ Máx } & Promedio \\
\hline A & $3 / 11$ & $10 / 11$ & 4 & 1400 & 431 \\
B & $7 / 18$ & $11 / 18$ & 40 & 182000 & 18702 \\
C & $6 / 11$ & $11 / 11$ & 200 & 4000 & 1272 \\
D & $4 / 11$ & $11 / 11$ & 28 & 450000 & 41202 \\
\hline
\end{tabular}

${ }^{\dagger}$ Muestras con presencia de Salmonella del total de muestras tomadas por región; ${ }^{\dagger \dagger}$ Muestras con presencia de $E$. coli del total de muestras tomadas por región; ' ${ }^{\xi}$ Unidades formadoras de colonia por $100 \mathrm{~mL}$ de muestra.

Los canales de uso agrícola del Valle de Culiacán se encuentran al aire libre, por lo que la contaminación puede tener diversos orígenes, como introducción de agua residual a los canales, descargas domésticas, y excretas de animales silvestres como reptiles y aves (Thurston et al., 2002). Según la Comisión Nacional del Agua (CONAGUA), las poblaciones menores de 2500 habitantes no requieren servicios de tratamiento de agua residual y pueden descargarse directamente en flujos de agua 
(CONAGUA, 2007). Durante el periodo de muestreo fue evidente la presencia de animales silvestres y ganado bovino en las cercanías de los canales; además, algunas comunidades rurales descargan aguas residuales sin tratamiento alguno hacia diversos cuerpos de agua.

No se pudo determinar la presencia de Salmonella en las 23 muestras de suelo analizadas. Sin embargo, este resultado no necesariamente sugiere la ausencia de la misma, ya que se ha reportado que las bacterias en ambientes hostiles entran en estado viable pero no cultivable, lo que dificulta su aislamiento en medios de cultivo selectivos (Caro et al., 1999). Además, Salmonella es capaz de sobrevivir y multiplicarse en el suelo por hasta un año (Winfield y Groisman, 2003). Entre los factores que determinan la sobrevivencia de la bacteria en el suelo están: tipo de suelo, grado de desecación, poblaciones de organismos depredadores y cantidad de materia orgánica presente en el mismo (Paluszac et al., 2003). Otra causa que dificulta el aislamiento de Salmonella de muestras de suelo es la alta concentración de microbiota natural. De Brito et al. (1995) encontraron bacterias, actinomicetes y hongos en concentraciones superiores a $12.5 \times 10^{12}, 3.8 \times$ $10^{5}$ y $6.4 \times 10^{4} \mathrm{UFC} \mathrm{mL}^{-1}$, respectivamente. Se considera que la ausencia de Salmonella en suelo puede deberse a que presentaban el fenómeno de estado viable pero no cultivable, o bien a una alta concentración de microbiota mixta del suelo y a la dificultad de aislar la bacteria con los métodos de cultivo empleados en esta investigación (Reissbrodt et al., 2000).

De las 20 cepas de Salmonella aisladas se encontraron los serotipos Typhimurium, Give, Anatum, Agona, Infantis, Oranienburg y Minnesota (Cuadro 2). En Sinaloa no se tienen reportes de la presencia de estos serotipos de Salmonella aquí aislados, lo cual expone la diversidad de Salmonella en agua de uso agrícola. Lo anterior sugiere la aplicación de medidas correctivas que prevengan la contaminación de hortalizas que son irrigadas con esta agua, además de que este tipo de contaminación pone en riesgo de infección a los trabajadores de campo.

En el presente estudio el serotipo Typhimurium fue aislado con mayor frecuencia, lo que coincide con lo reportado por Beier et al. (2004) quienes lo describen como el serotipo de mayor prevalencia en el ambiente y el causante del mayor número de brotes epidemiológicos por el consumo de agua y alimentos contaminados. Este serotipo ocasiona entre 40 y $70 \%$ de los casos de salmonelosis reportados en Estados Unidos. Esto puede deberse al amplio rango de hospederos que la bacteria puede utilizar, en los cuales se incluyen, además de los humanos, ganado bovino, porcino, equino, y una amplia diversidad de aves silvestres y de corral (Refsum et al., 2002).

Cuadro 2. Cepas de Salmonella y E. coli aisladas de agua de uso agrícola y su perfil de resistencia a los antimicrobianos, en el Valle de Culiacán, Sinaloa, México.

\begin{tabular}{|c|c|c|c|c|c|c|}
\hline \multirow[b]{2}{*}{ Cepas } & \multicolumn{6}{|c|}{ Perfil de resistencia a los antimicrobianos } \\
\hline & $\mathrm{Amp}_{\bar{\dagger}}$ & $\operatorname{Cip}_{\dagger}$ & $\mathrm{Tm} / \mathrm{Sx}$ & Tet & $\begin{array}{c}\text { Est } \\
t+t t_{t}\end{array}$ & Gen \\
\hline \multicolumn{7}{|l|}{ Salmonella } \\
\hline Typhimurium & $0 / 13$ & $0 / 13$ & $0 / 13$ & $12 / 13$ & $0 / 13$ & $0 / 13$ \\
\hline Give & $0 / 1$ & $0 / 1$ & $0 / 1$ & $0 / 1$ & $0 / 1$ & $0 / 1$ \\
\hline Anatum & $0 / 1$ & $0 / 1$ & $0 / 1$ & $0 / 1$ & $1^{*} / 1$ & $0 / 1$ \\
\hline Agona & $0 / 1$ & $0 / 1$ & $0 / 1$ & $0 / 1$ & $0 / 1$ & $0 / 1$ \\
\hline Infantis & $0 / 2$ & $0 / 2$ & $0 / 2$ & $0 / 2$ & $0 / 2$ & $0 / 2$ \\
\hline Oranienburg & $0 / 1$ & $0 / 1$ & $0 / 1$ & $0 / 1$ & $0 / 1$ & $0 / 1$ \\
\hline Minnesota & $0 / 1$ & $0 / 1$ & $0 / 1$ & $0 / 1$ & $0 / 1$ & $0 / 1$ \\
\hline $\begin{array}{c}\text { Escherichia } \\
\text { coli }\end{array}$ & $\mathrm{NE}$ & NE & $\mathrm{NE}$ & $\begin{array}{c}9 / 46 \\
1^{\xi} / 46\end{array}$ & $\begin{array}{l}38 / 46 \\
8^{\xi} / 46\end{array}$ & $\begin{array}{c}1 / 46 \\
23^{\xi} / 46\end{array}$ \\
\hline
\end{tabular}

También se aislaron los serotipos Oranienburg, Infantis y Anatum, los cuales han estado involucrados en brotes de gastroenteritis por el consumo de frutas y hortalizas frescas. Salmonella Oranienburg, ha sido responsable de brotes por el consumo de melón en Estados Unidos y Canadá (Deeks et al., 1998), y los serotipos Infantis y Anatum fueron responsables de un brote por consumo de germinados de alfalfa en Estados Unidos (Feng, 1997). Los serotipos mencionados figuran dentro de los 20 más frecuentemente asociados con brotes diarreicos en Estados Unidos (CDC, 2004). En México, los principales serotipos relacionados en brotes de gastroenteritis por el consumo de agua y alimentos contaminados, son: Typhimurium, Enteritidis, Derby, Agona y Anatum (Gutiérrez-Cogco et al., 2000).

\section{Cuantificación de Escherichia coli}

Del total de muestras de agua analizadas, $98 \%(50 / 51)$ resultaron positivas para E. coli (Cuadro 1). Buckwalter et al. (2006) reportaron la presencia de coliformes fecales y E. coli con promedio de $5 \times 10^{4} \mathrm{UFC} / 100 \mathrm{~mL}$ y de $3.9 \mathrm{x}$ $10^{4} \mathrm{UFC} / 100 \mathrm{~mL}$ respectivamente, en muestras de agua de río. La sobrevivencia de $E$. coli en el ambiente es variable, pero no sobrepasa de un día; sin embargo, las altas concentraciones que aparentemente se mantienen debido a la constante descarga de su hábitat primario, a los mamíferos y a los cuerpos de agua superficial (Winfield y Groisman, 2003). Aun cuando E. coli se considera indicador de contaminación fecal, en la actualidad se conocen al menos seis grupos patógenos de esta especie responsables de ocasionar diversas enfermedades por el 
consumo de agua y alimentos contaminados (Brooks et al., 2005).

De la misma manera que para Salmonella, no fue posible el aislamiento de $E$. coli del suelo, probablemente por inhibición por la microbiota bacteriana en la muestra.

\section{Perfil de resistencia a los antimicrobianos}

El Cuadro 2 muestra el perfil de resistencia de las cepas de Salmonella aisladas durante el estudio. Las 20 cepas de Salmonella fueron susceptibles a ampicilina, ciprofloxacino y trimetoprim-sulfametoxazol. De estas cepas, $60 \%$ presentaron resistencia a tetraciclina y todas éstas corresponden al serotipo Typhimurium. Estos resultados concuerdan con lo publicado por el Sistema de Monitoreo Nacional de Resistencia a Antimicrobianos de Bacterias Entéricas (NARMS, siglas en inglés) que establece que la resistencia en Salmonella es dependiente del serotipo y que Typhimurium es el que presenta mayores niveles de resistencia (NARMS, 2005). Su persistencia en el ambiente incrementa el continuo contacto con antimicrobianos y genera una selección natural que evade el ataque de éstos (Refsum et al., 2002).

Las cepas aisladas presentaron mayor resistencia a la tetraciclina, ya que este antimicrobiano exhibe actividad contra diversos grupos de bacterias, motivo por el cual es ampliamente utilizado para terapia en infecciones humanas y para la prevención y control de infecciones en plantas y animales (Miko et al., 2005). La Agencia de Protección Ambiental de los Estados Unidos (U.S. EPA), tiene registrado el uso de tetraciclina y estreptomicina en la agricultura, y sólo en América Latina que incluye a México, se ha permitido el uso de gentamicina (Vidaver, 2002).

Sólo una de las 20 cepas aisladas presentó resistencia intermedia a estreptomicina. Este antimicrobiano es de uso limitado en medicina clínica, pero ha adquirido importancia como promotor de crecimiento en animales y para el control de enfermedades bacterianas en plantas (Miko et al., 2005). Puesto que los genes de resistencia a tetraciclina y estreptomicina se encuentran en plásmidos, pueden ser transferidos por conjugación a otros microorganismos (Hamada et al., 2002). Pezella et al. (2004) demostraron la presencia de material genético (Transposón Tn5393 con una secuencia de inserción IS1133) en cepas de Salmonella, que sólo había sido descrito en cepas de Erwinia amylovora. Al respecto, los investigadores sugirieron que Salmonella importa dichos elementos genéticos a partir de patógenos de plantas, probablemente durante una contaminación cruzada de alimentos para animales; además sugieren que pueden presentarse escenarios óptimos para que ocurra la transmisión de resistencia entre patógenos zoonóticos y patógenos de plantas (Pezella et al., 2004).

A 46 cepas de E. coli se les evaluó el perfil de resistencia a tetraciclina, estreptomicina y gentamicina (Cuadro 2); $19.5 \%(9 / 46)$ fueron resistentes a tetraciclina y una presentó resistencia intermedia. De las cepas de $E$. coli, $82.6 \%$ (38/46) fueron resistentes a estreptomicina y $17.4 \%(8 / 46)$ presentaron resistencia intermedia. El 2.1 $\%$ (1/46) presentó resistencia a gentamicina y $50 \%$ (23/46) presentaron resistencia intermedia. La resistencia a estreptomicina se ha reportado como el fenotipo más frecuente en cepas de E. coli, determinada en $76 \%$ de aislados de animales y $87 \%$ de aislados de humanos (Šeputiene et al., 2006), lo que concuerda con los resultados aquí obtenidos, ya que se determinó resistencia en $82.6 \%$ de las cepas de $E$. coli aisladas. También se ha reportado que $E$. coli exhibe perfiles de resistencia a tetraciclina, estreptomicina y gentamicina, en 29.9, 6.2 y $3.1 \%$, respectivamente (Musgrove et al., 2006).

De las cepas de E. coli analizadas, $50 \%$ presentaron resistencia intermedia a gentamicina. Díaz et al. (2006) demostraron que las bacterias Gram negativas no pueden adquirir fácilmente los genes que confieren altos niveles de resistencia, ya que éstos son nativos de bacterias Gram positivas; sin embargo, bacterias como $E$. coli producen enzimas modificadas que pueden degradar el antibiótico como una alternativa de resistencia intermedia, la cual puede ser precursora de la resistencia clínica (Phillips et al., 2004).

Aunque el uso de los antimicrobianos está regulado, ha persistido la resistencia incluso en microorganismos comensales de infantes que nunca han sido tratados con antibióticos (Karami et al., 2006). Drudy et al. (2006) reportaron que Enterobacter sakazakii se asoció con casos de meningitis en infantes que se alimentaron con fórmula láctea en polvo; además, esta bacteria es naturalmente resistente a todos los macrólidos, licomicina, clindamicina, rifampicina, entre otros, $\mathrm{y}$ ha generado resistencia a ampicilina debido a la adquisición de elementos genéticos trasponibles. Esto confirma que ocurre la transferencia horizontal de elementos genéticos móviles entre microorganismos; un solo plásmido puede acarrear genes de resistencia para diferentes antibióticos, lo que da como resultado la multirresistencia mostrada por cepas de $E$. coli y Salmonella (Hamada et al., 2002). 


\section{Concentración mínima inhibitoria a sulfato de cobre}

Todas las cepas evaluadas presentaron altos niveles de resistencia, los cuales fluctuaron entre 1200 a 1600 $\mu \mathrm{g} \mathrm{mL}^{-1}$ de $\mathrm{CuSO}_{4} \cdot 5 \mathrm{H}_{2} \mathrm{O}$ (Cuadro 3). Martin et al. (2004) evaluaron la $\mathrm{CMI}$ de $\mathrm{CuSO}_{4} \cdot 5 \mathrm{H}_{2} \mathrm{O}$ en cepas de Xanthomonas campestris pv. Vesicatoria y consideraron como cepas resistentes a las que crecían a una concentración de $200 \mu \mathrm{g} \mathrm{mL} \mathrm{m}^{-1}$. Las cepas de Salmonella aisladas en el presente trabajo muestran un rango de resistencia a $\mathrm{CuSO}_{4} \cdot 5 \mathrm{H}_{2} \mathrm{O}$ de 6 a 8 veces mayor que las cepas de Xanthomonas evaluadas por Martin et al. (2004).

Cuadro 3. Concentración mínima inhibitoria (CMI) a $\mathrm{CuSO}_{4} \cdot 5 \mathrm{H}_{2} \mathrm{O}$ de los serotipos de Salmonella aislados de agua de uso agrícola, en el Valle de Culiacán, Sinaloa, México.

\begin{tabular}{lc}
\hline Serotipo & CMI a CuSO ${ }^{\cdot} \cdot 5 H_{2} \mathbf{O}(\mu \mathbf{g} / \mathbf{m L})$ \\
\hline & $1600^{\dagger}\left(4^{\dagger \dagger} / 13^{\dagger \dagger}\right)$ \\
Typhimurium & $1550(3 / 13)$ \\
& $1500(5 / 13)$ \\
Agona & $1350(1 / 13)$ \\
Oranienburg & $1600(1 / 1)$ \\
Anatum & $1550(1 / 1)$ \\
Infantis & $1200(1 / 1)$ \\
& $1650(1 / 2)$ \\
Minnesota & $1400(1 / 2)$ \\
Give & $1600(1 / 1)$ \\
\hline
\end{tabular}

${ }^{\dagger} \mathrm{CMI}$ de $\mathrm{CuSO}_{4} \cdot 5 \mathrm{H}_{2} \mathrm{O}$. ${ }^{\dagger \dagger}$ Cepas del mismo serotipo inhibidas a la concentración de $\mathrm{CuSO}_{4} \cdot 5 \mathrm{H}_{2} \mathrm{O}$ indicada. iti Número total de cepas del mismo serotipo.

La constante exposición a sales de cobre favorece la selección de cepas resistentes mediante manifestación de genes de resistencia, los cuales ejercen su acción por medio del "secuestro" y acumulación de cobre (gen cop), así como por flujo dependiente de energía y acumulación baja del mismo (gen pco) (Mandal y Argüello, 2003). Por tanto, es necesario realizar investigaciones adicionales para determinar los mecanismos por los cuales se induce dicha resistencia.

\section{CONCLUSIONES}

Con los resultados del presente trabajo se demuestra la existencia de los microorganismos buscados en el agua de riego, con una mayor frecuencia de $E$. coli (en $98 \%$ de las muestras) que de Salmonella (39 \%), de la cual se identificaron siete serotipos. Ambos microorganismos evidenciaron diversos niveles de resistencia a los antibióticos, y todas las cepas de Salmonella resultaron resistentes al sulfato de cobre.

\section{AGRADECIMIENTOS}

A la Q.F.B. Célida Isabel Martínez Rodríguez y al M.C. Julio Henoc Monjardín Heráldez por su colaboración.

\section{BIBLIOGRAFÍA}

Association of Official Agricultural Chemists, AOAC (1998) Método Oficial para la Determinación de Cobre por Absorción Atómica. Método 965.09. 2.6.01 p.

American Public Health Association, APHA (1999) Standard Methods for the Examination of Water and Wastewater. 20th ed. Washinghton, DC. 9222 B; 9260 B.

American Public Health Association, APHA (2001) Compendium of Methods for the Microbiological Examination of Foods. 4th ed Washington, DC.

Bada-Alambedji R, A Fofana, M Seydi, A J Akakpom (2006) Antimicrobial Resistance of Salmonella Isolated from Poultry Carcasses in Dakar (Senegal). Brazil. J. Microbiol. 37:510-515.

Beier R C, S D Pillai, T D Phillips, R L Ziprin (2004) Preharvest and Postharvest Food Safety: Contemporary Issues and Future Directions. 1st ed. Wiley-Blackwell. pp:3-42.

Beuchat L R (1996) Pathogenic Microorganisms Associated with Fresh Produce. J. Food Protect. 59:204-216.

Brooks G F, J S Butel, S A Morse (2005) Microbiología Médica de Jawetz, Melnick y Adelberg. 18a ed. trad. 23a ed. en inglés. El Manual Moderno. pp:159-188, 247-254.

Buck J W, R R Walcott, L R Beuchat (2003) Recent Trends in Microbiological Safety of Fruits and Vegetables. Plant Health Progress. http://www.apsnet.org/online/feature/safety/

Buckwalter T F, T M Zimmerman, J W Fulton (2006) Fecal-indicator bacteria in the Allegheny, Monongahela, and Ohio rivers and selected tributaries, Allegheny County, Pennsylvania, 2001-2005. U.S. Geological Survey Scientific Investigations Report pp: 51265127. http://pubs.usgs.gov/sir/2006/5216/pdf/sir2006-5216.pdf

Caro A, P Got, J Lesne, S Binard, B Baleux (1999) Viability and virulence of experimentally stressed nonculturable Salmonella typhimurium. Appl. Environ. Microbiol. 65:3229-3232.

Centers for Disease Control and Prevention, CDC (2002) Multistate outbreaks of Salmonella serotype Poona infections associated with eating cantaloupe from Mexico - United States and Canada, 2000 -- 2002. Morbility and Mortality Weekly Report, MMWR 51:1044-1047. http://www.cdc.gov/mmwr/preview/mmwrhtml/mm5146a2.htm

Centers for Disease Control and Prevention (CDC) (2004) Salmonella: Annual Summary. Department of Health and Human Services, Centers for Diseases Control and Prevention, National Center for Infectious Diseases. Division of Bacterial And Mycotic Diseases. Foodborne and Diarrheal Diseases Branch. Atlanta, Georgia http://www.cdc.gov/ncidod/dbmd/phlisdata/salmtab/2004/Salmon ellaAnnualSummary \% 202004.pdf

Chatterjee A K, M P Starr (1972) Transfer among Erwinia spp. and other enterobacteria of antibiotic resistance carried on R Factors. J. Bacteriol. 112:576-584.

Chiu C H, J T Ou (1996) Rapid identification of Salmonella serovars in feces by specific detection of virulence genes, invA and spvC, by an enrichment broth culture-multiplex PCR combination assay. J. Clin. Microbiol. 34:2619-2622.

Comisión Nacional del Agua, CONAGUA (2007) Estadísticas del Agua en México. ISBN 978-968-817-852-2. 1a ed. 256 p.

Deeks S, A Ellis, B Ciebin, R Khakhria, M Naus, J Hockin (1998) Salmonella Oranienburg, Ontario. Can. Comm. Dis. Rep. 24:177-179. 
De Brito A M, S Gagne, H Antoun (1995) Effect of compost on rhizosphere microflora of the tomato and on the incidence of plant growth-promoting Rhizobacteria. Appl. Environ. Microbiol. 61:194-199.

Díaz M, R Kent, A Cloeckaert, R Siebeling (2006) Plasmid-mediated high-level gentamicin resistance among enteric bacteria isolated from pet turtles in Louisiana. Appl. Environ. Microbiol. 72:306312.

Dirección General de Epidemiología, DGE (2006) Información Epidemiológica de Morbilidad 2005. ISBN 970-721-323-X. México http://www.dgepi.salud.gob.mx (23 de febrero de 2009)

Drudy D, N R Mullane, T Quinn, P G Wall, S Fanning (2006) Enterobacter sakazakii: An emerging pathogen in powdered infant formula. Clin. Infect. Dis. 42:996-1002.

Duffy E A, L M Lucia, J M Kells, A Castillo, S D Pillai, G R Acuff (2005) Concentration of Escherichia coli and genetic diversity and antibiotic resistance profiling of Salmonella isolated from irrigation water, packing shed equipment, and fresh produce in Texas. J. Food Prot. 68:70-79.

Feng $P$ (1997) A Summary of Background Information and Foodborne Illness Associated with the Consumption of Sprouts. U.S. Food and Drug Administration. Center for Food Safety and Applied Nutrition. Washington.

http://www.cfsan.fda.gov/ mow/sprouts.html (23 de Febrero de 2009).

Gill C J, W E Keene, J C Mohle-Boetani, J A Farrar, P L Waller, C G Hahn, P R Cieslak (2003) Alfalfa seed decontamination in a Salmonella outbreak. Emerging Infect. Dis. 9:474-479.

Gutiérrez-Cogco L, V E Montiel, P P Aguilera, A M González (2000) Serotipos de Salmonella identificados en los servicios de salud de México. Salud Púb. Méx. 42:490-495.

Hamada K, H Tsuji , K Oshima (2002) Identification and characterization of transferable integron-mediated antibiotic resistance among Salmonella serovar Typhimurium and Salmonella serovar Infantis isolates from 1991 to 2002. J. Infect. Dis. $55: 135-138$.

Karami N, F Nowrouzian, I Adlerberth, E Wold (2006) Tetracycline resistence in Escherichia coli and persistence in the infantile colonic microbiota. Antimicrob. Agents Chemoth. 50:156-161.

Mandal A, Argüello J (2003) Functional roles of metal binding domains of the Archaeoglobus fulgidus $\mathrm{Cu}+-\mathrm{ATPase}$ CopA. Biochemistry 42:11040-11047.

Martin H L, V A Hamilton, R A Kopittke (2004) Copper tolerance in australian populations of Xanthomonas campestris pv. vesicatoria contributes to poor field control of bacterial spot of pepper. Plant Dis. 88:921-924.

Miko A, K Pries, A Schroetes, R Helmuth (2005) Molecular mechanisms of resistance in multidrug-resistant ser. of Salmonella enterica isolated from foods in Germany. J. Antimicrobial Chem. 56:1025-1033.

Musgrove M, D Jones, J Northcutt, N Cox, M Harrison, P Ferdorka, S Ladely (2006) Antimicrobial resistance in Salmonella and Escherichia coli isolated from commercial shell eggs. Poultry Sci. Assoc. 85:1665-1669.

National Antimicrobial Resistance Monitoring System, NARMS (2005) http://www.ars.usda.gov/Main/docs.htm?docid=14491 (23 de febrero de 2009).
National Committee for Clinical Laboratory Standard, NCCLS (1997) Métodos de Dilución para un Estudio de Susceptibilidad Antimicrobiana para Bacterias de Crecimiento Aeróbico. 4a ed. Norma Aprobada. M7-A4. Vol. 17, No. 2.

National Commitee for Clinical Laboratory Standard, NCCLS (2003) Performance standards for Antimicrobial Disk Susceptibility Tests. Approved Standard. 8th Ed. M2-A8; Vol. 23, No. 1.

NOM-001-ECOL-1996. Norma Oficial Mexicana Ecológica. Que establece los límites máximos permisibles de contaminantes en las descargas de aguas residuales en aguas y bienes nacionales.

Paluszac Z, A Ligocka, B B Breza, H Olszewska (2003) The survival of selected fecal bacteria in peat soil amended with slurry. Electronic J. Polish Agric. Universities. Vol 6, No. 2. http://www.ejpau.media.pl/volume6/issue2/animal/art-04.html

Pezella C, A Ricci, E DiGiannatale, I Luzzi, A Carattoli (2004) Tetracycline and streptomycin resistence genes, transposons, and plasmids in Salmonella enterica isolates from animals in Italy. Antimicrob. Agents Chemoth. 48:903-908.

Phillips I, M Casewell, T Cox, B De Groot, C Friis, R Jones, C Nightingale, R Preston, J Waddell (2004) Does the use of antibiotics in food animals pose a risk to human health? A critical review of published data. J. Antimicrobial Chemoth. 53:28-52.

Refsum T, E Heir, G Kapperud, T Vardund, G Holstad (2002) Molecular epidemiology of Salmonella enterica Serovar Typhimurium isolates determined by pulsed-field gel electrophoresis: comparison of isolates from avian wildlife, domestic animals, and the environment in Norway. Appl. Environ. Microbiol. 68:5600-5606.

Reissbrodt R, H Tschäpe, $\mathbf{R}$ A Kingsley, P H Williams (2000) Resuscitation by ferroxiamine E of stressed Salmonella enterica serovar Typhimurium from soil and water microcosms. Appl. Environ. Microbiol. 66:4128-4130.

Secretaría de Agricultura, Ganadería, Desarrollo Rural, Pesca y Alimentación, SAGARPA (2007) Guía de Plaguicidas Autorizados de Uso Agrícola. Comisión Nacional de Sanidad Agropecuaria, Servicio Nacional de Sanidad, Inocuidad y Calidad Agroalimentaria. http://148.245.191.4/guiaplag/(S(tosky0qc04uoo1zyfevhq145))/In icio.aspx (23 de febrero de 2009).

Šeputiene V, M Ružauskas, P Žlabys, E Sužiedeliene (2006) Characterization of streptomycin resistance determinants in Lithuanian Escherichia coli isolates. Biologija 2:14-17.

Thurston E J A, P Watt, S E Down, R Enriquez, I L Pepper, C P Gerba (2002) Detection of protozoan parasites and microsporidia in irrigation waters used for crop production. J. Food Prot. $65: 378-382$.

University of Maryland - Food and Drug Administration, UM-FDA (2002) Buenas Prácticas Agrícolas. Sección II http://jifsan.umd.edu/pdf/gaps_es/SECCI_N_II.pdf

Vidaver K A. (2002) Uses of antimicrobials in plant agriculture. Clin. InfecT. Dis. 34:107-110.

Winfield M D, E A Groisman (2003) Role of nonhost environments in the lifestyles of Salmonella and Escherichia coli. Appl. Environ. Microbiol. 69:3687-3694. 